ONLINE MUTATION REPORT

\title{
Novel splicing associations of hereditary colon cancer related DNA mismatch repair gene mutations
}

\author{
E Renkonen, H Lohi, H J Järvinen, J-P Mecklin, P Peltomäki
}

J Med Genet 2004;41:e95 (http://www.jmedgenet.com/cgi/content/full/41/7/e95). doi: 10.1136/jmg.2003.017269

$\mathrm{H}$ ereditary non-polyposis colon cancer (HNPCC) is a multi-organ cancer syndrome associated with hereditary defects in DNA mismatch repair (MMR). To date, more than 400 predisposing mutations have been deposited in the ICG-HNPCC mutation database, mostly affecting MLH1 $\quad(\approx 50 \%), \quad$ MSH2 $\quad(\approx 40 \%)$, and MSH6 $\quad(\approx 10 \%)$ (www.nfdht.nl/). Over half of all HNPCC-linked MMR gene mutations consist of nonsense or frameshift changes that result in premature termination codons. ${ }^{1}$ Such transcripts are subject to nonsense mediated mRNA decay, a surveillance mechanism whose purpose is to protect the organism against dominant negative or gain of function effects of truncated proteins. ${ }^{2}$ Furthermore, some nonsense as well as missense and even silent changes can alter pre-mRNA splicing by introducing or disrupting exonic splicing enhancer or exonic splicing silencer sequences. ${ }^{3-5}$ By doing so, the mutations may promote the skipping or inclusion of exons in which they are located. Evidence in support of this mechanism exists at least for certain nonsense and missense mutations in MLH $1 .{ }^{67}$ Most mutations that affect splicing consist of single nucleotide substitutions in the classical splice sites at intron/ exon junctions; such mutations are particularly common in $M L H 1$, constituting one third of all germline mutations in this gene.

In this work, a strategy based on RNA was chosen for mutation screening in families with hereditary non-polyposis colorectal cancer, since a previous study on the same population indicated that $75 \%$ of $M L H 1$ and $M S H 2$ mutations were detectable as aberrant sized transcripts. ${ }^{8}$ This report focuses on novel splicing associations of the mutations discovered.

\section{MATERIALS AND METHODS \\ Patient specimens}

Families F73, F95, and F65 meeting the Amsterdam I criteria for hereditary non-polyposis colorectal cancer $^{9}$ were screened for predisposing mutations. F73 was part of a population based series, whose clinical and molecular characteristics not related to splicing have been addressed previously. ${ }^{8}{ }^{10}$ Two HNPCC families with known predisposing mutations in MLHI (F13 with $\mathrm{g} \rightarrow \mathrm{a}$ at nucleotide 454-1 at splice acceptor site of exon 6, and F83 with R659X in exon $17^{811}$ ), another two with mutations in MSH2 (F38 with del CA at nucleotide 1550 in exon 10, F25 with ins GT at nucleotide 1860 in exon $12^{8}$ ) as well as two healthy control individuals were included in the analysis of splice changes. This study was based on RNA and DNA extracted from Epstein-Barr virus transformed lymphoblasts, supplemented with RNA from uncultured lymphocytes as necessary (the general splice patterns of lymphoblasts and lymphocytes have been shown to be comparable ${ }^{12}$ ).

All human specimens were obtained after informed consent according to the guidelines of the institutional review boards.

\section{Key points}

- As part of an effort to identify predisposing mutations in families with hereditary non-polyposis colorectal cancer, full length lymphoblastoid cDNAs of $M L H 1$ and $\mathrm{MSH} 2$ were cloned and the products analysed for mutations and splice changes.

- In one family, a nonsense mutation (R100X in MLHI exon 3) was discovered through its association with skipping of exons not related to the mutation: deletion of one or more exons occurred in 8/14 (57\%) among clones originating from the mutated alleles against $3 / 33(9 \%)$ among clones originating from healthy alleles of two carriers of this mutation $(p=0.001)$.

- Another mutation affecting the same exon (del AGAA at nucleotide 210) was also associated with multiple exon skipping in a single transcript, but without an overall increase in the frequency of splice events. Five other mutations (two in $\mathrm{MLHl}$ and three in $\mathrm{MSH}$ ) were not associated with aberrant splicing.

- Splice events in the mutant MLH1 transcripts clustered around exons 9, 10, and 14-17, which also represent areas involved in alternative splicing.

- Healthy alleles of mutation carriers did not differ from those of healthy control individuals in regard to splicing.

- Our data suggest that some MLH1 transcripts containing mutations are distinguished by an aberrant splicing phenomenon, whose occurrence may depend on mutation location. This splicing may have a biological role, and it may aid mutation diagnostics by distinguishing mutation containing cDNA clones.

\section{RT-PCR and cloning of CDNA}

RNA was reverse transcribed with oligo-dT and SuperScript II according to the manufacturer's instructions (SuperScript ${ }^{\mathrm{TM}}$ First-Strand Synthesis System for RT-PCR, Invitrogen). Full length cDNA of MLHI (2.3 kb) and MSH2 (2.8 kb) was amplified with primers RT-Lfl and RT-Lrl (for MLHI) and RT-Sfl and RT-Srl (for MSH2) (table 1), ${ }^{13}$ using Expand Long Template PCR System (Roche). The products were used for direct sequencing to detect mutations as well as for cloning into $\mathrm{pCR}^{\circledR} \mathrm{II}-\mathrm{TOPO}{ }^{\circledR}$ vector taking advantage of TOPO TA Cloning ${ }^{\circledR}$ system (Invitrogen). The resulting plasmids were

Abbreviations: HNPCC, hereditary non-polyposis colorectal cancer; ICG-HNPCC, International Collaborative Group on HNPCC; MLHI, MutL homologue 1; MMR, DNA mismatch repair; MSH2, MutS homologue 2; MSH6, MutS homologue 6; RT-PCR, reverse transcription PCR 
Table 1 Primers used to screen $M L H 1$ and MSH2 cDNA for mutations and splice changes

\begin{tabular}{|c|c|c|c|c|}
\hline $\begin{array}{l}\text { Primer } \\
\text { name }\end{array}$ & Direction & Sequence & Location & $\begin{array}{l}\text { Fragment } \\
\text { length }\end{array}$ \\
\hline \multicolumn{5}{|l|}{ MLHI } \\
\hline RT-Lf1* & Forward & 5'-CATCTAGACGTTTCCTTGGCTCTTC-3' & $5^{\prime}$ UTR & \multirow{2}{*}{\} $1093 \mathrm{bp}$} \\
\hline MLH1-12R & Reverse & 5'-GCAAGTCCTGGTAGCAAAGT-3' & Exon 12 & \\
\hline $\mathrm{MLH} 1-\mathrm{BF}$ & Forward & 5'-AAGGGACCCAGATCACGG-3' & Exon 5 & \multirow{2}{*}{ \} $536 \mathrm{bp}$} \\
\hline MLH1-BR & Reverse & 5'-CTCCAGGATGCTCTCCTC-3' & Exon 11 & \\
\hline $\mathrm{MLH} 1-\mathrm{CF}$ & Forward & 5'-CGGGTGCAGCAGCACATCG-3' & Exon 11 & \multirow{3}{*}{\} $1446 \mathrm{bp}$} \\
\hline $\mathrm{RT}-\mathrm{Lr} 1^{*}$ & Reverse & 5'-TAAAGGAATACTATCAGAAGGCAAGTATA-3' & 3' UTR & \\
\hline \multicolumn{4}{|c|}{ 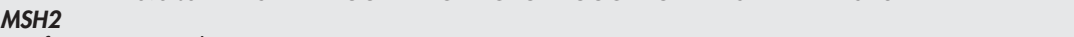 } & \\
\hline RT-Sfl * & Forward & 5'-GGCGGGAAACAGCTIAGTGGGTGTG-3' & 5' UTR & \multirow{2}{*}{\} $1504 \mathrm{bp}$} \\
\hline MSH2-CR & Reverse & 5'-TGAGATTAGGATCAAATGAAGG-3' & Exon 9 & \\
\hline Sf3* & Forward & 5'GCAGAATTGAGGCAGACTIT-3' & Exon 7 & \multirow{2}{*}{\} $1282 \mathrm{bp}$} \\
\hline MSH2-ER & Reverse & 5' -CAGTTGGTATCTGATTGGC-3' & Exon 14 & \\
\hline $\mathrm{MSH} 2-\mathrm{EF}$ & Forward & 5'-TTGGAGAAAGGACAAGGAAG-3' & Exon 12 & \multirow{2}{*}{ \}1084 bp } \\
\hline $\mathrm{RT}-\mathrm{Sr} 1^{*}$ & Reverse & 5'-CCCATGGGCACTGACAGTTAACACTATG-3' & 3' UTR & \\
\hline
\end{tabular}

used to transform XL1-Blue (Stratagene, La Jolla, CA) cells, and recombinant clones were identified based on white colour on Xgal containing plates. Among positive colonies, all available or a representative number (average 25) of discrete colonies were selected for DNA isolation and subsequent analysis.

\section{Analysis of cDNA clones for splicing}

To screen for possible size alterations, DNA isolated from individual clones was amplified in three overlapping fragments each for MLH1 and MSH2 (table 1) and run through $1.5-2.5 \%$ agarose gels. The identity of skipped or inserted exons was determined by sequencing. The allelic origin of transcripts (fig 2) was established using targeted assays for the mutations themselves or their primary splicing consequences, including size fractionation by agarose gel electrophoresis (for $\Delta 3, \Delta 6$, and $\Delta 17$ ), TaqI (for R100X and R659X) or ApaLI digestion of PCR products (for the MSH2 exon 10 mutation), and single strand conformation polymorphism analysis (for Q593X). For $M L H 1$, allelic origin was independently determined taking advantage of a common polymorphism, I219V.

\section{Studies of circular RNA}

RNA was reverse transcribed with random hexamers, and the cDNA was subjected to one round or nested PCR using primers whose orientation made amplification from linear species impossible. To test for circular products involving MLH1 exons 9 and 10, the following primers were used: 10R, 5'-GTTTTTGGGCAAATAGGCTG-3' and 10F, 5' -ACACACCCA TTCCTGTACC-3'; for a seminested reaction, 9R, 5'-GTTT GCATTGGATATGTAACC-3' was combined with 10F. The region around $M L H I$ exons 14 and 15 was studied with primers 14R, 5'-TGCCAAGGCCCACTGAGGATTC-3' and 14F, 5'-CTTGGCACAGCATCAAACC-3'; for a seminested reaction, 14R was combined with 15F, 5'-GAAGAACTGTTCTAC CAGATACTC- $3^{\prime}$.
RT-Lf1 and MLH1-12R (exons 1-12)
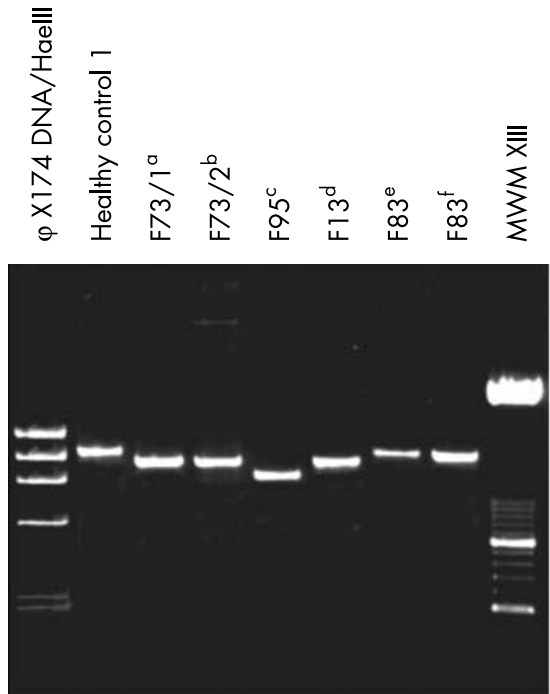

$\begin{array}{rrr}\Delta 10 \Delta 10 & \Delta 3 & \Delta 6 \\ & \Delta 9\end{array}$
MLH1-BF and MLH1-BR (exons 5-11)
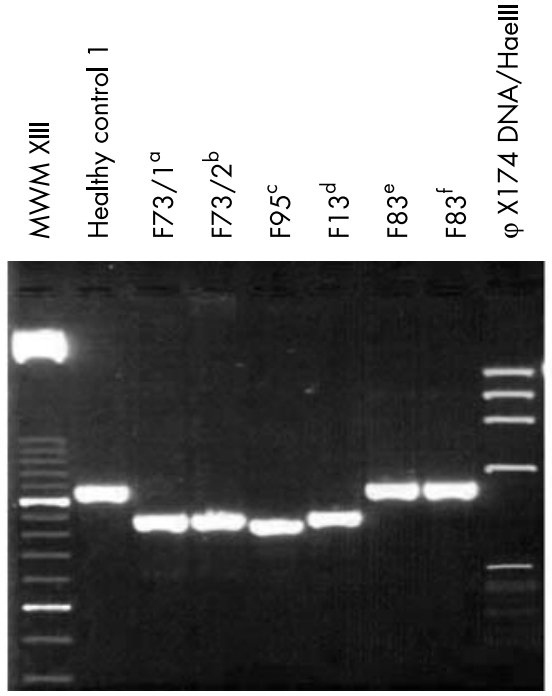

$\Delta 10 \Delta 10 \Delta 9 \quad \Delta 6$
MLHI-CF and RT-Lr1 (exons 11-19)
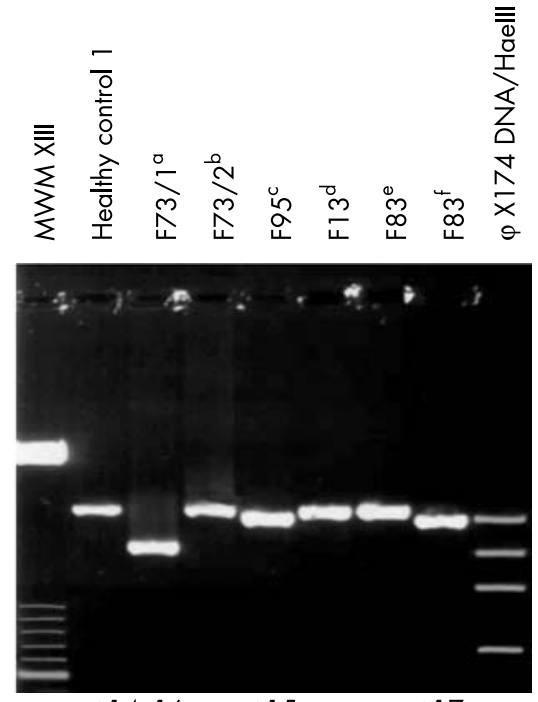

$\Delta 14-16$

$\Delta 15$

Figure 1 Examples of splice abnormalities observed in cDNA clones from representatives of HNPCC families F73 (F73/1 and F73/2), F95, F13, and F83, as well as a healthy control. All clones representing HNPCC cases correspond to alleles carrying $M L H 1$ mutations and are marked with superscript letters a-f in this figure as well as in fig 2. For each clone, MLHI cDNA was amplified in three overlapping fragments with primers indicated above each panel (see table 1 for primer sequences) and the products were run through $1.5 \%$ (left and right panels) or $2.5 \%$ (middle panel) agarose gels. 

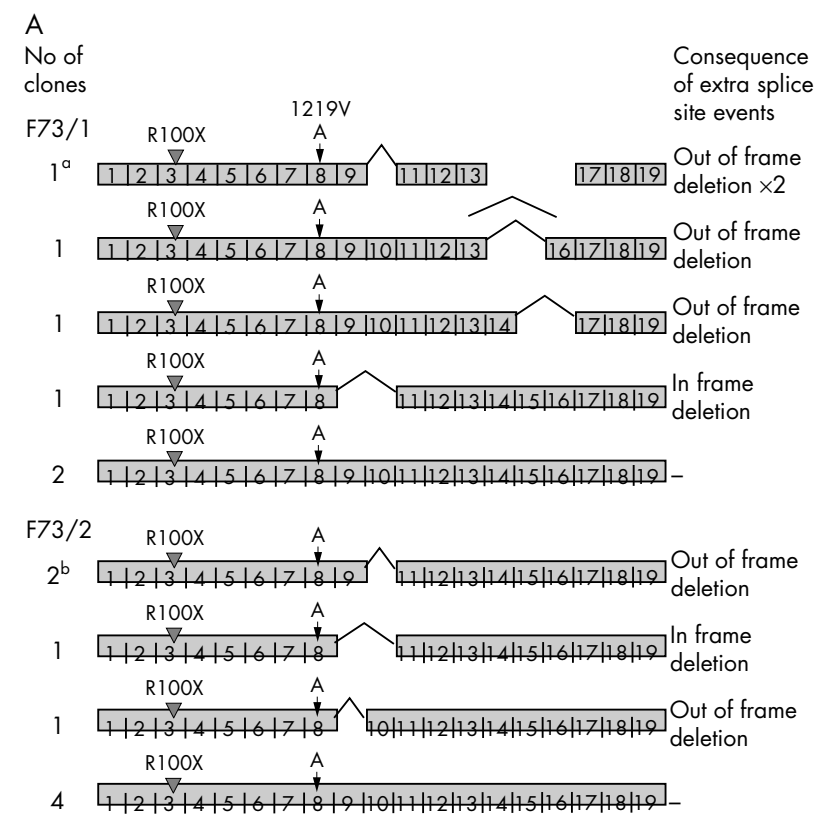

F95 (del AGAA at c. 70, splice acceptor of exon 3)

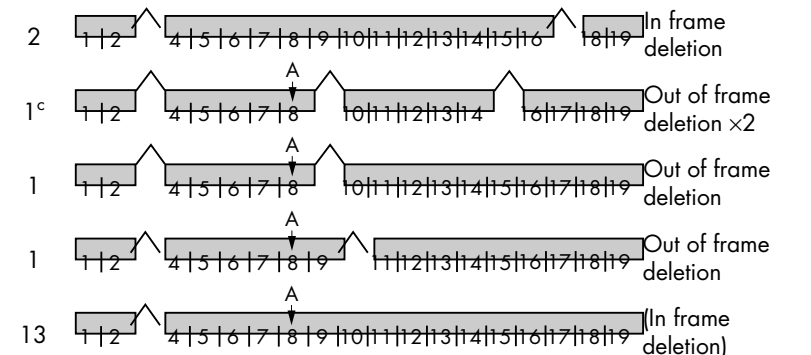

F13 (g > a at nt. 454-1, splice acceptor of exon 6)

$5^{\text {d }} 412131415$ (t)

F83 ( $\mathrm{g}>\mathrm{a}$ at nt. 454-1, splice acceptor of exon 6)

A R659X
A

$2^{\mathrm{e}}$

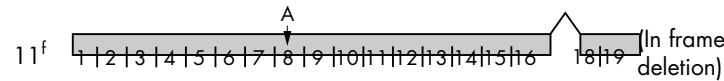

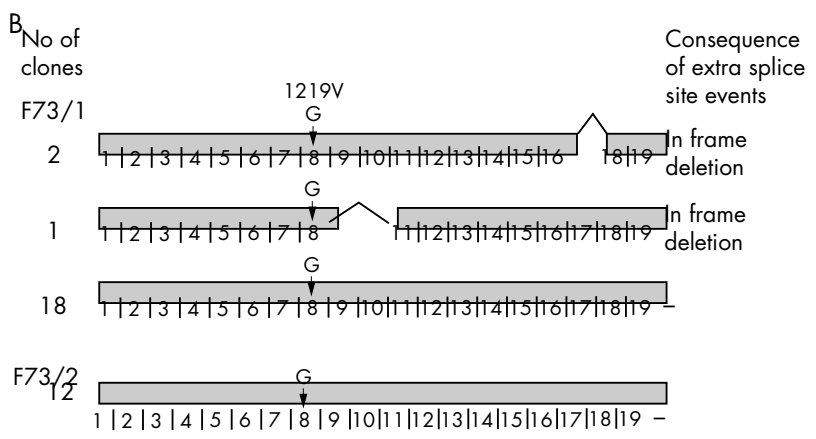

F95
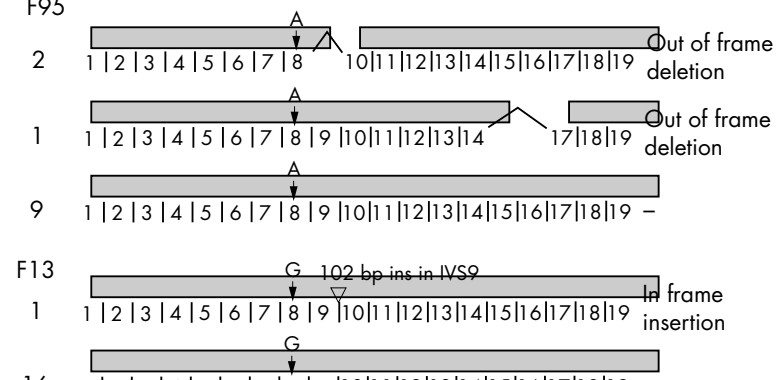

16 1|2|3|4|5|6|7|8|9|10|11|12|13|14|15|16|17|18|19-

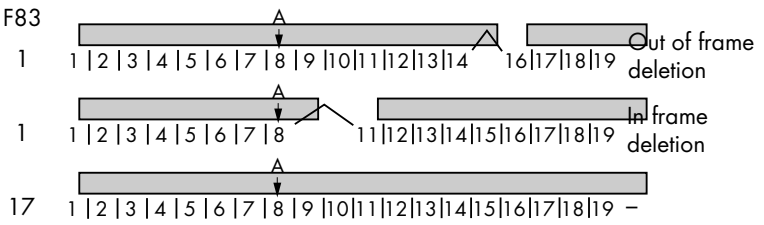

D Control 1

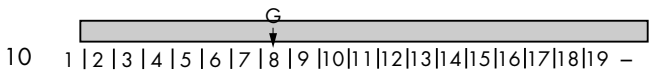

Control 2

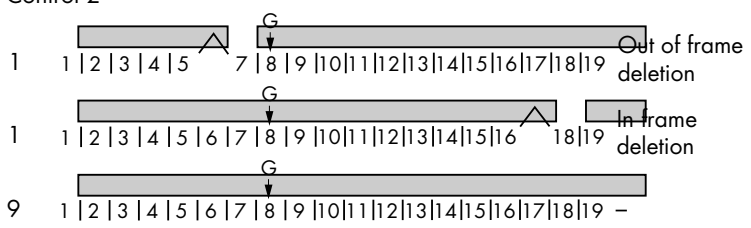

C
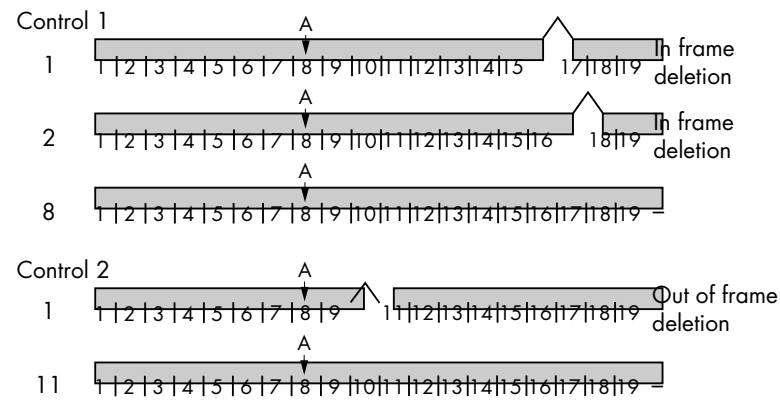

Figure 2 Schematic summary of splice changes detected in $M L H 1$ cDNA clones. The allelic transcripts of mutation carriers (figs $2 A$ and B) are primarily distinguished by the presence (fig $2 \mathrm{~A}$ ) or absence (fig $2 \mathrm{~B}$ ) of the predisposing mutation or its primary splicing consequence and secondarily by the base (A or G) present at the polymorphic site in codon 219 (exon 8). In F73 (F73/1 and F73/2) and F13, base A at this codon independently identifies the mutant transcripts (those derived from the healthy alleles of the same individuals carry G), whereas F95 and F83 are uninformative due to constitutional homozygosity (both mutant and healthy transcripts carry A). The codon 219 polymorphism defines the allelic origin of transcripts from two healthy controls (figs $2 \mathrm{C}$ and D). All splice changes except one (an insertion in a transcript derived from the healthy allele in F13) consist of deletions of one or more exons. The number of clones with a given splice pattern is indicated to the left of each bar. Gel images of splice forms a-f are shown in fig 1. The effect of splice events on the reading frame is given to the right of each bar (parentheses in fig 2A indicate the primary splicing consequence of the predisposing mutation). 
Table 2 Splicing consequences of HNPCC associated $M L H 1$ and $M S H 2$ mutations

\begin{tabular}{|c|c|c|c|c|c|c|}
\hline \multirow[b]{3}{*}{ Mutation } & \multirow[b]{3}{*}{ Family } & \multirow[b]{3}{*}{ Primary splicing effect } & \multirow{3}{*}{$\begin{array}{l}\text { Frequency of } \\
\text { mutant clones* }\end{array}$} & \multicolumn{3}{|c|}{ Number of clones studied for splicing } \\
\hline & & & & \multirow[b]{2}{*}{ Total } & \multicolumn{2}{|c|}{ Transcripts with extra splice events ${ }^{\dagger}$} \\
\hline & & & & & Mutant & Normal \\
\hline \multicolumn{7}{|l|}{ MLHI } \\
\hline $\mathrm{C} \rightarrow \mathrm{T}$ at $\mathrm{n} 298, \mathrm{c} 100$, exon 3 (R100X) & 73 & None & $5 / 38(13 \%)$ & 47 & $8 / 14(57 \%)^{\ddagger}$ & $3 / 33(9 \%)^{\ddagger}$ \\
\hline Del AGAA at n 210, c 70, exon 3 & 95 & $\Delta 3$ (in frame) & $18 / 30(60 \%)$ & 30 & $5 / 18(28 \%)$ & $3 / 12(25 \%)$ \\
\hline $\mathrm{C} \rightarrow \mathrm{T}$ at $\mathrm{n}$ 975, c 659, exon 17 (R659X) & 83 & $\begin{array}{l}\text { None } \\
\Delta 17 \text { (in frame) }\end{array}$ & $\begin{array}{l}1 / 31(3 \%) \\
11 / 31(35 \%)\end{array}$ & 32 & $\begin{array}{l}0 / 2(0 \%) \\
0 / 11(0 \%)\end{array}$ & $2 / 19(11 \%)$ \\
\hline $\mathrm{g} \rightarrow \mathrm{a}$ at $\mathrm{n} 454-1$, splice acceptor of exon 6 & 13 & $\Delta 6$ (out of frame) & $3 / 18(17 \%)$ & 22 & $0 / 5(0 \%)$ & $1 / 17(6 \%)$ \\
\hline \multirow[t]{2}{*}{ Healthy control 1} & - & - & - & $11(\mathrm{~A})^{5}$ & - & $3 / 11(27 \%)$ \\
\hline & & & & $10(G)^{\S}$ & - & $0 / 10(0 \%)$ \\
\hline \multirow[t]{2}{*}{ Healthy control 2} & - & - & - & $12(A)^{5}$ & - & $1 / 12(8 \%)$ \\
\hline & & & & $11(G)^{\S}$ & - & $2 / 11(18 \%)$ \\
\hline \multicolumn{7}{|l|}{$\mathrm{MSH} 2$} \\
\hline $\begin{array}{l}\mathrm{C} \rightarrow \mathrm{T} \text { at } \mathrm{n} 1777 \text {, c } 593 \text {, exon } 12 \text { (Q593X) } \\
\text { - with puromycin }\end{array}$ & 65 & None & $\begin{array}{l}1 / 32(3 \%) \\
2 / 17(12 \%)\end{array}$ & $\begin{array}{l}32 \\
17\end{array}$ & $\begin{array}{l}0 / 1(0 \%) \\
0 / 2(0 \%)\end{array}$ & $\begin{array}{l}0 / 31(0 \%) \\
2 / 15(13 \%)\end{array}$ \\
\hline Ins GT at n 1860, c 620, exon 12 & 25 & None & $3 / 40(8 \%)$ & 40 & $0 / 3(0 \%)$ & $1 / 37(3 \%)$ \\
\hline Del CA at $\mathrm{n} 1550$, c 518 , exon 10 & 38 & None & $1 / 35(3 \%)$ & 35 & $0 / 1(0 \%)$ & $0 / 34(0 \%)$ \\
\hline Healthy control 1 & - & - & - & 24 & - & $0 / 24(0 \%)$ \\
\hline \multicolumn{7}{|c|}{$\begin{array}{l}\text { *Among a representative number of clones (18-38) randomly selected for analysis of the predisposing defect. } \\
\text { †Among all clones known to be derived either from the mutation containing or normal allele. Note that even though the frequency of extra splice events in both } \\
\text { types of transcripts is unbiased, relative proportion of mutation containing versus normal transcripts is not, since mutation containing clones, which were normally } \\
\text { heavily underrepresented, were in some cases actively selected for analysis of splicing. } \\
\ddagger p=0.001 \text { by Fisher's exact test ( } 2 \text { tailed). } \\
\S A \text { and G refer to the polymorphic base present at codon } 219 \text {. }\end{array}$} \\
\hline
\end{tabular}

\section{RESULTS \\ Identification of predisposing mutations by cDNA cloning}

We originally set out to identify predisposing mutations in three families with hereditary non-polyposis colorectal cancer (F73, F95, and F65). In the first two families, immunohistochemical data (lack of MLHl protein in tumour tissue) were available, pinpointing the defective gene. Amplification of the $2.3 \mathrm{~kb}$ coding region of $M L H I$ in a single fragment by RT-PCR revealed no aberrant sized fragments by electrophoresis through $1.5 \%$ agarose gels (data not shown). Sequencing of RT-PCR products showed a normal sequence in F73, whereas in F95 a double sequence was present, suggesting a heterozygous change. To separate the cDNA products of mutant and healthy alleles, the cDNAs were cloned, and DNA isolated from individual clones was amplified in three overlapping fragments (table 1) to screen for possible size alterations. A proportion of clones-a minority for F73 and a majority for F95-showed shortened products (see fig 1). A few deletion containing clones for each individual were sequenced entirely. In F73, a recurring point mutation $(\mathrm{C} \rightarrow \mathrm{T}$ at codon 100, nucleotide 298 of MLHI, designated as R100X) was found, accompanied by deletion of unrelated exons, whereas F95 showed consistent skipping of exon 3 without any recurring point mutation. Sequencing of the respective exons in genomic DNA demonstrated R100X as a heterozygous change in the affected representative from F73, while a heterozygous deletion of AGAA at codon 70, three nucleotides downstream of the 5' end of MLHI exon 3 was present in F95, consistent with a disruption of a splice site. The mutations cosegregated with disease in both families, compatible with their role as predisposing mutations. Besides F73, the Rl00X mutation is known to occur in at least three further families from the United States and Europe (www.nfdht.nl) ${ }^{14}$ whereas the MLH1 mutation of F95 is novel.

A similar cDNA based approach turned out unsuccessful in F65. However, genomic exon specific sequencing revealed a novel nonsense mutation, $\mathrm{C} \rightarrow \mathrm{T}$ at codon 593, nucleotide 1777, in exon 12 of $M S H 2$, designated as Q593X. This mutation could not be detected in cDNA (with or without cloning) because of severe instability of the respective mRNA: a retrospective single strand conformation polymorphism analysis of 31 originally isolated cDNA clones showed that only one carried the predisposing mutation (see table 2 ).

\section{Association of DNA mismatch repair gene mutations with aberrant splicing}

Prompted by the unexpected splicing consequences of R100X, we included families F73, F95, and F65, together with four additional families with known predisposing mutations (F13 and F83 with MLH1 as well as F25 and F38 with MSH2 mutations) in a detailed analysis of splice changes (table 2, figs 1 and 2). In $M L H 1$, four basic types of splice events were observed. First, deletion of exon 3 in F95 and exon 6 in F13 were compatible with the disruption of a regular exonic and intronic splice site, respectively, through germline mutations. Second, deletion of exon 17 in F83 was likely to reflect the inactivation of an intra-exonic splicing enhancer as a result of the R659X mutation, even though no candidate exonic splicing enhancer sequence could be identified at this site by a prediction program (http://genes.mit.edu/burgelab/ rescue-ese/). Third, skipping events in transcripts corresponding to the healthy alleles (the most common being $\Delta 17$ and $\Delta 9-10)$ were compatible with previous RT-PCR reports of alternative splicing. ${ }^{12} 1516$ Finally, R100X in F73 was associated with multiple deletion of exons other than those harbouring the predisposing mutation, which constituted a fourth and novel category. Importantly, samples from two affected members of this family (F73/1 and F73/2) both showed the phenomenon: deletion of one or multiple exons occurred in 8/14 (57\%) among clones originating from the mutated alleles against 3/33 (9\%) among clones originating from the healthy alleles $(p=0.001)$. While some splice events in the mutant transcripts involved exons that may also be affected by alternative splicing $(\Delta 9, \Delta 10, \Delta 9-10, \Delta 15-16)$, others affected exons that were never involved in healthy transcripts $(\Delta 14-15, \Delta 14-16)$. Unlike mutation containing transcripts, the frequency of splice events in transcripts originating from healthy alleles of these two patients was not elevated as compared to healthy controls. In the entire series, the proportion of transcripts with splice events was similar for healthy alleles from mutation carriers (9/81, 11\%) and healthy control individuals $(6 / 44,14 \%)$ (table 2, fig 2). 
Our cloning experiments revealed severe underrepresentation of mutant mRNA as a common feature of all three MSH2 mutations investigated, which limited the number of mutant transcripts available for studies of splicing (table 2). In the case of Q593X, translation inhibitor Puromycin was used $(200 \mu \mathrm{g} / \mathrm{ml}$ for 6.5 hours $)$ to suppress nonsense mediated mRNA decay, with only a weak effect. No splice events were observed in the mutant MSH2 transcripts. All MSH2 cDNA clones analysed from the healthy control individual also showed the full length product. While the low number of mutant transcripts did not allow comparison between $M L H 1$ and $M S H 2$ in regard to the occurrence of aberrant splicing, splice events in healthy transcripts were less frequent for MSH2 (1/126, 1\%) than MLH1 $(12 / 125,12 \%) \quad\left(\mathrm{p}<0.01\right.$ by $\chi^{2}$ test) (table 2, Puromycin experiment not included).

\section{Role of circular RNA formation in exon skipping}

To date, a few human genes have been shown to exhibit multiple exon skipping as a result of circular RNA formation. ${ }^{17-21}$ In this phenomenon, exons are joined at consensus splice sites, but in an order different from that in genomic DNA. Although the mechanism leading to circular splicing products is unknown, it may be provoked by structural aberrations, such as a deletion mutation in the DMD gene. ${ }^{22}$ To address RNA circularisation in carriers of R100X, a series of RT-PCR experiments was performed on lymphoblastoid and lymphocyte RNA using primers facing away from one other and selecting MLHI exons 9-10 and 14-15 for our target regions, because of their frequent involvement in splice events (fig 2). By this design, amplification products would be obtained from circular RNA transcripts only, whereas linear RNA species could not serve as templates for PCR. No products consistent with circular RNA were observed (data not shown), thus failing to support this mechanism as an explanation for multiple exon skipping in our case. Our experiments do not exclude the possibility of circular RNA products not involving these target exons.

\section{DISCUSSION}

The phenomenon observed for R100X in MLHl-aberrant mRNA splicing of multiple exons unrelated to the mutation-is exceptional and to our knowledge, has not been reported for the MMR genes before. Based on the present relatively limited set of mutations, the occurrence of this abnormality may depend on mutation site and type, perhaps reflecting altered secondary structure of the mutant premRNA, as proposed for another disorder (maple syrup urine disease) displaying multiple exon skipping for an unknown cause. ${ }^{23}$ The presence of a premature termination codon in itself was clearly insufficient to explain the splicing phenomenon, since among six nonsense or frameshift mutations tested, only Rl00X showed this associated aberration. Possible local changes in conformation may be compatible with the observation that the only other mutation associated with the skipping of multiple unrelated exons ( $\Delta 9$ and $\Delta 15)$, although without an overall increase of splice events, was the $4 \mathrm{bp}$ deletion mutation with the in-frame deletion of the same exon ( $\mathrm{MLHl}$ exon 3 ) as the primary splicing consequence (fig 2).

In rare instances, exons that are skipped may be present as circular RNA products, ${ }^{17-21}$ and a connection to alternative splicing has been proposed. ${ }^{19}$ While we did not obtain convincing evidence of RNA circularisation in our study, the regions involved in multiple exon skipping in mutant transcripts overlapped with those commonly affected by alternative splicing in normal human tissues (fig 2 ) $^{12}{ }^{15}{ }^{16}$. The biological significance of alternative splice products is unknown. Out of frame products are typically unstable $(\text { table } 2)^{24}$, while in-frame products (such as MLHI $\Delta 9-10,{ }^{25}$
$\Delta 16$ and $\Delta 17^{26}$ ) may be otherwise unable to perform their tasks in MMR. More often than restoring the reading frame, altered splicing may induce premature stop codons. ${ }^{4}$ A recent survey of mRNAs deposited in various databases revealed that $35 \%$ of alternative transcripts contained premature termination codons, raising the possibility that alternative splicing connected with nonsense mediated mRNA decay may be a means of regulating protein expression. ${ }^{27}$ In view of this, it may be important that in our study, $11 / 15$ (73\%) of extra splice events observed in mutant $M L H 1$ transcripts were out of frame, as compared to $6 / 15(40 \%)$ among those occurring in transcripts derived from healthy alleles, even though the difference did not reach statistical significance.

It is presently unknown if the splicing abnormality we describe has any independent influence on clinical manifestations, such as the severity of hereditary non-polyposis colorectal cancer. F73 with R100X showed a relatively late mean age at onset as compared to F95 with in-frame deletion of the same exon and a "milder" form of multiple exon skipping ( 53 and 46 years, respectively). This difference could reflect the marked decrease of the mutant gene product in the former case, perhaps enhanced by the splicing abnormality, and the shortage of the mutant product could reduce possibilities for dominant negative inhibition. ${ }^{28}$

All mutations resulting in premature termination codons were associated with a severe reduction in the proportion of the respective transcripts, whereas the allelic transcripts from healthy control individuals were expressed equally (table 2, fig 2). This needs to be taken into account in cDNA based approaches for mutation screening. From the diagnostic point of view, splicing alterations may provide a valuable shortcut to the detection of mutations whose transcripts are too unstable to be visible by simple RT-PCR, making CDNA cloning necessary. As demonstrated for Rl00X, more than half of clones containing deletions also harboured the predisposing mutation, whereas the clones containing mutations were strongly underrepresented (13\%) among all clones. In such instances, instead of random selection, multiple exon deletions may provide a way to single out the likely mutation containing cDNA clones for sequencing.

\section{ACKNOWLEDGEMENTS}

We thank Saila Saarinen for expert technical assistance, Jinmin Miao for cell cultures, Kirsi Pylvänäinen, Tuula Lehtinen, and Heli SurmaAho for assistance with sample collection, and Tuomo KukkolaRenkonen for computer support.

\section{Authors' affiliations \\ E Renkonen, H Lohi, P Peltomäki, Department of Medical Genetics, FIN- 00014 University of Helsinki, Finland \\ H J Järvinen, Second Department of Surgery, Helsinki University Central Hospital, FIN-00290 Helsinki, Finland \\ J-P Mecklin, Department of Surgery, Jyväskylä Central Hospital, FIN- 40620 Jyväskylä, Finland}

This study was supported by the Sigrid Juselius Foundation, the Academy of Finland, the Finnish Cancer Foundation, the Science Foundation of the University of Helsinki, the Paulo Foundation, and the NIH (grant CA82282).

Conflicts of interest: none declared.

Correspondence to: Dr P Peltomäki, Department of Medical Genetics, Biomedicum Helsinki, PO Box 63 (Haartmaninkatu 8), FIN-00014 University of Helsinki, Finland; Paivi.Peltomaki@Helsinki.Fi

\section{REFERENCES}

1 Peltomäki P, Vasen HFA. The International Collaborative Group on Hereditary Nonpolyposis Colorectal Cancer. Mutations predisposing to hereditary nonpolyposis colorectal cancer: database and results of a collaborative study. Gastroenterology 1997;113:1146-58 
2 Frischmeyer PA, Dietz HC. Nonsense-mediated mRNA decay in health and disease. Hum Mol Genet 1999;8:1893-1900.

3 Maquat LE. The power of point mutations. Nat Genet 2001;27:5-6.

4 Cartegni L, Chew SL, Krainer A. Listening to silence and understanding nonsense: exonic mutations that affect splicing. Nat Rev Genet 2002;3:285-98.

5 Faustino NA, Cooper TA. Pre-mRNA splicing and human disease. Genes Dev 2003; 17:419-37.

6 Nyström-Lahti M, Holmberg M, Fidalgo P, Salovaara R, de la Chapelle A, Jiricny J, Peltomäki P. Missense and nonsense mutations in codon 659 of MLH1 cause aberrant splicing of messenger RNA in HNPCC kindreds. Genes Chromosomes Cancer 1999;26:1-4.

7 Stella A, Wagner A, Shito K, Lipkin SM, Watson P, Guanti G, Lynch HT, Fodde R, Liu B. A nonsense mutation in $M L H 1$ causes exon skipping in three unrelated HNPCC families. Cancer Res 2001:61:7020-4.

8 Holmberg $M$, Kristo $P$, Chadwick RB, Mecklin J-P, Järvinen $H$, de la Chapelle A, Nyström-Lahti M, Peltomäki P. Mutation sharing, predominant involvement of the $\mathrm{MLHl}$ gene, and description of four novel mutations in hereditary nonpolyposis colorectal cancer. Hum Mutat 1998;11:482.

9 Vasen HFA, Mecklin J-P, Khan PM, Lynch HT. The International Collaborative Group on Hereditary Non-Polyposis Colorectal Cancer (ICG-HNPCC). Dis Colon Rectum 1991; 34:424-5.

10 Renkonen ET, Zhang Y, Lohi H, Salovaara R, Abdel-Rahman W, Nilbert M, Aittomäki $\mathrm{K}$, Järvinen $\mathrm{H}$, Mecklin J-P, Lindblom A, Peltomäki P. Altered expression of $\mathrm{MLH1}, \mathrm{MSH} 2$, and $M S H 6$ in predisposition to hereditary nonpolyposis colorectal cancer. J Clin Oncol 2003;21:3629-37.

11 Nyström-Lahti M, Wu Y, Moisio A-L, Hofstra RMW, Osinga J, Mecklin J-P, Järvinen HJ, Leisti J, Buys CHCM, de la Chapelle A, Peltomäki P. DNA mismatch repair gene mutations in 55 kindreds with verified or putative hereditary non-polyposis colorectal cancer. Hum Mol Genet 1996;5:763-9.

12 Genuardi M, Viel A, Bonora D, Capozzi E, Bellacosa A, Leonardi F, Valle R, Ventura A, Pedroni $M$, Boiocchi M, Neri G. Characterization of $M L H 1$ and $\mathrm{MSH} 2$ alternative splicing and its relevance to molecular testing of colorectal cancer susceptibility. Hum Genet 1998;102:15-20.

13 Nomura S, Sugano K, Kashiwabara H, Taniguchi T, Fukayama N, Fujita S, Akasu T, Moriya Y, Ohhigashi S, Kakizoe T, Sekiya T. Enhanced detection of deleterious and other germline mutations of $h M S H 2$ and $h M L H 1$ in Japanese hereditary nonpolyposis colorectal cancer kindreds. Biochem Biophys Res Commun 2000;271:120-9.

14 Samowitz WS, Curtin K, Lin HH, Robertson MA, Schaffer D, Nichols M, Gruenthal K, Leppert MF, Slattery ML. The colon cancer burden of genetically defined hereditary nonpolyposis colon cancer. Gastroenterology 2001;121:830-8.

15 Charbonnier F, Martin C, Scotte M, Sibert L, Moreau V, Frebourg T. Alternative splicing of $M L H 1$ messenger RNA in human normal cells. Cancer Res 1995;55:1839-41.
16 Palmirotta R, Veri MC, Curia MC, Aceto G, D'Amico F, Esposito DL, Arcuri $P$, Mariani-Costantini R, Messerini L, Mori S, Cama A, Battista P. Transcripts with splicings of exons 15 and 16 of the hMLH1 gene in normal lymphocytes: implications in RNA-based mutation screening of hereditary non-polyposis colorectal cancer. Eur J Cancer 1998;34:927-30.

17 Nigro JM, Cho KR, Fearon ER, Kern SE, Ruppert JM, Oliner JD, Kinzler KW, Vogelstein B. Scrambled exons. Cell 1991;64:607-13.

18 Cocquerelle C, Daubersies P, Majerus M-A, Kerckaert J-P, Bailleul B. Splicing with inverted order of exons occurs proximal to large introns. $E M B O J$ 1992;11:1095-8.

19 Zaphiropoulos PG. Exon skipping and circular RNA formation in transcripts of the human cytochrome P-450 2C18 gene in epidermis and of the rat androgen binding protein gene in testis. Mol Cell Biol 1997; 17:2985-93.

20 Li X-F, Lytton J. A circularized sodium-calcium exchanger exon 2 transcript. J Biol Chem 1999:274:8153-60.

21 Surono A, Takeshima Y, Wibawa T, Ikezawa M, Nonaka I, Matsuo M. Circular dystrophin RNAss consisting of exons that were skipped by alternative splicing. Hum Mol Genet 1999;8:493-500.

22 Gualandi $F$, Trabanelli C, Rimessi P, Calzolari E, Toffolatti L, Patarnello T, Kunz G, Muntoni F, Ferlini A. Multiple exon skipping and RNA circularisation contribute to the severe phenotypic expression of exon 5 dystrophin deletion. J Med Genet 2003;40:e100.

23 Fisher CW, Fisher CR, Chuang JL, Lau KS, Chuang DT, Cox RP. Occurrence of a 2-bp (AT) deletion allele and a nonsense (G-to-T) mutant allele at the E2 (DBT) locus of six patients with maple syrup urine disease: multiple-exon skipping as a secondary effect of the mutations. Am J Hum Genet 1993;5:414-24.

24 Xia L, Shen W, Ritacca F, Mitri A, Madlensky L, Berk T, Cohen Z, Gallinger S, Bapat B. A truncated $h M S H 2$ transcript occurs as a common variant in the population: implications for genetic diagnosis. Cancer Res 1996;56:2289-92.

25 Trojan J, Zeuzem S, Randolph A, Hemmerle C, Brieger A, Raedle J, Plotz G Jiricny J, Marra G. Functional analysis of $h M L H l$ variants and HNPCC-related mutations using a human expression system. Gastroenterology 2002;122:21 1-19.

26 Nyström-Lahti $M$, Perrera $C$, Räschle $M$, Panyushkina-Seiler E, Marra G, Curci A, Quaresima B, Costanzo F, D'Urso M, Venuta S, Jiricny J. Functional analysis of $\mathrm{MLH1}$ mutations linked to hereditary nonpolyposis colon cancer. Genes Chromosomes Cancer 2002;33:160-7.

27 Lewis BP, Green RE, Brenner SE. Evidence for the widespread coupling of alternative splicing and nonsense-mediated mRNA decay in humans. Proc Natl Acad Sci U S A 2003;100:189-92.

28 Jager AC, Bisgaard ML, Myrhoi T, Bernstein I, Rehfeld JF, Nielsen FC. Reduced frequency of extracolonic cancers in hereditary nonpolyposis colorectal cancer families with monoallelic hMLH1 expression. Am J Hum Genet 1997;61:129-38. 